\title{
A Review of High-Risk Rapid Weight Loss Behaviors with Assessment of Food Intake and Anthropometric Measurements in Combat Sport
} Athletes

\author{
Mehnoosh Samadi ${ }^{1}$, Miaad Chaghazardi ${ }^{2}$, Amir Bagheri ${ }^{1}$, Sheno Karimi ${ }^{2}$, Yahya Pasdar ${ }^{1}$, Mohammad \\ Hozoori $^{3}$ and Shima Moradi ${ }^{1, *}$ \\ ${ }^{1}$ Department of Nutritional Sciences, Research Center for Environmental Determinants of Health (RCEDH), Health Institute, Kermanshah University of Medical Sciences, \\ Kermanshah, Iran \\ ${ }^{2}$ Student Research Committee, Nutritional Science Department, School of Nutritional Science and Food Technology, Kermanshah University of Medical Sciences, \\ Kermanshah, Iran \\ ${ }^{3}$ Research Center of Nutrition Science, Qom University of Medical Sciences, Qom, Iran \\ "Corresponding author: Department of Nutritional Sciences, Research Center for Environmental Determinants of Health (RCEDH), Health Institute, Kermanshah University of \\ Medical Sciences, Kermanshah, Iran. Email: shima.moradi@kums.ac.ir
}

Received 2018 October 23; Revised 2019 September 05; Accepted 2019 October 05.

\begin{abstract}
Context: In most combat sports, athletes are classified according to their body weight, and many of them attempt to lose weight quickly.

Objectives: Since the effects of rapid weight loss (RWL) on competitive performance are somewhat ambiguous, this study aims to review high-risk behaviors used for RWL, to assess food intake and anthropometric data in combat sports athletes, and to investigate the negative effects of RWL on physiological and health-related parameters.

Methods: This systematic review study was conducted by searching the PubMed, Science Direct and Scopus databases using keywords, including (combat sports, RWL, high-risk behaviors) and (food intake, anthropometric measurements) from 2001 to 2017. After screening based on the title and abstract of identified studies, 17 articles met our inclusion criteria and were included in this review.

Results: The results of the studies indicated a high prevalence of RWL among athletes, which was often due to reduced body fluids. At the same time, lower-level athletes often used more dangerous methods, such as fasting, skipping meal, and fluid restriction. This method can negatively affect athletes' mental status and athletic performance.

Conclusions: Regarding the negative effects of short-term adjustment of weight on physiological and mental function, further studies suggest athletes to consume a balanced and varied diet including all food groups.
\end{abstract}

Keywords: Combat Sports, Weight Loss, Behavior

\section{Context}

In almost all combat sports, athletes are classified according to their body weight to be admitted into tournaments $(1,2)$. Many athletes in combat sports such as boxing, judo, wrestling and karate decrease their body weight over few days (ranging from 5 to 7 days) prior to competition. This weight loss allows them to compete in a lower weight class than their usual weight, thus facing smaller and weaker competitors (3-6). In almost all combat sports, the "official weighing" occurs 3 to 24 hours before the competition, to ensure that athletes are categorized in the same weight class (7). For many athletes around the world, there is a direct relationship between success and low body weight (8). However, various studies have indicated adverse effects of rapid weight loss (RWL) on body health (9-15). Despite the side effects of RWL (such as loss of short-term memory, strength, concentration and selfesteem, as well as increased confusion, anger, fatigue, depression and isolation $)(6,16,17)$, there is a high prevalence of aggressive and harmful methods of RWL in many combat sports, such as wrestling (6), judo $(3,18,19)$, jujitsu (19), karate (19), taekwondo (19-21) and boxing (22). Although there is no doubt about the negative effects of RWL on physiological and health-related parameters (5), its effects on competitive performance are somewhat ambiguous, since many factors, including time of weight loss, recovery time after the weighing, and diet type, may affect the response 
to weight loss (23). RWL can be affected by various factors such as coaches, parents, nutritionists, experienced athletes, teammates, and doctors (24).

\section{Objectives}

As the decision to lose weight quickly can lead to some high-risk behaviors in athletes, the aim of this study was to review the evidence on the prevalence and types of methods for RWL, high-risk behaviors, dietary intake and anthropometric data in combat sports.

\section{Methods}

This study was designed based on the Preferred Reporting Items for the Systematic Reviews and Meta-Analyses (PRISMA) protocol (25).

\subsection{Data Sources}

This review article investigated reputable scientific electronic databases such as Scopus, Science Direct, and PubMed to find related publications from 2001 to 2017. Two researchers independently performed literature search using the medical subject headings (MeSH) and non-MeSH keywords "rapid weight loss" OR "combat sports" OR "highrisk behaviors" AND "food intake" OR "anthropometric measurements".

\subsection{Study Selection}

For this purpose, descriptive-analytical, case-control, and cross-sectional studies were included in this review study. We excluded review, meta-analysis, randomized clinical trial, letters, comments, short communication, ecological studies and animal studies. We considered studies assessing effects of RWL behaviors on food intake and anthropometric measurements.

A total of 138 articles were found in initial strategic search using the mentioned keywords. Then,10 duplicated studies were excluded. After screening based on interest topic, 76 irrelevant article were excluded whose hypotheses did not assess effects of RWL behaviors on food intake and anthropometric measurements. We considered other studies $(n=52)$ for evaluation with more details, among which we did not include any irrelevant study, including animal studies $(n=1)$, interventional studies $(n=18)$ and review studies $(n=13)$. In this regard, 3 articles were excluded, since they did not evaluate the desired effect and outcome. Overall, 17 articles were eligible to be included in this review study (Figure 1).

\subsection{Assessment of the Study Quality}

The studies quality was assessed using the STROBE statement, to assess the quality of observational studies. This scale examined 22 points for the title, abstract, introduction, methods, results, and discussion sections of each of observational studies. In this respect, 18 items were common among all observational studies and the other were specific for cohort, case-control, or cross-sectional studies (26). The details of this checklist have been published and are freely available on the websites of PLoS Medicine at http://www.plosmedicine.org/, Annals of Internal Medicine at http://www.annals.org/, and Epidemiology at http://www.epidem.com/. Information on the STROBE Initiative is available at www.strobe-statement.org.

\subsection{Data Extraction}

The studies information was extracted in the results part, including studies characteristics, prevalence and rate of RWL and common methods used, effects of RWL on physiological status and health-related parameters, anthropometric status, athletic performance, and assessment of dietary intake in RWL periods.

\section{Results}

\subsection{Studies Characteristics}

In this literature review, 17 relevant studies were found in which 8 studies were conducted in Europe $(8,9,14,15$, 27-30), 7 studies in America (3, 19, 31-35) and two of them in Asia $(24,36)$. The number of participants varied from 7 to 822 among the reviewed studies. The participants of the five studies included both genders $(3,8,27,31,34)$, five studies included only men $(9,28,33,35,36)$ and other studies did not determine the type of gender $(14,15,19,24,29,30$, $32)$. Nine studies were conducted on the adolescents $(8,9$, $14,24,28,30,32,34,35)$, five studies on the adults $(15,19,27$, $31,33)$, and the other on both of them, the adolescents and the adults $(3,29,36)$. Six studies examined judo $(3,14,19$, $24,27,35)$, five studies taekwondo $(19,30,31,34)$, five studies wrestle $(27,32,33,35,36)$, four studies box $(9,15,24,28)$, two studies jujitsu (19, 35), two studies mixed marital arts (29, 35 ), one study karate (19), and one of them considered any type of elite sport (Table 1) (8). In the current study, all reviewed studies were considered high quality based on the STROBE statement.

\subsection{Prevalence of RWL and Common Methods Used}

This review study indicated that the prevalence of RWL among the reviewed studies was reported to be 31.25 to $86 \%$. Common methods were used for RWL in the reviewed studies, including dietary restrictions (for example fasting, 


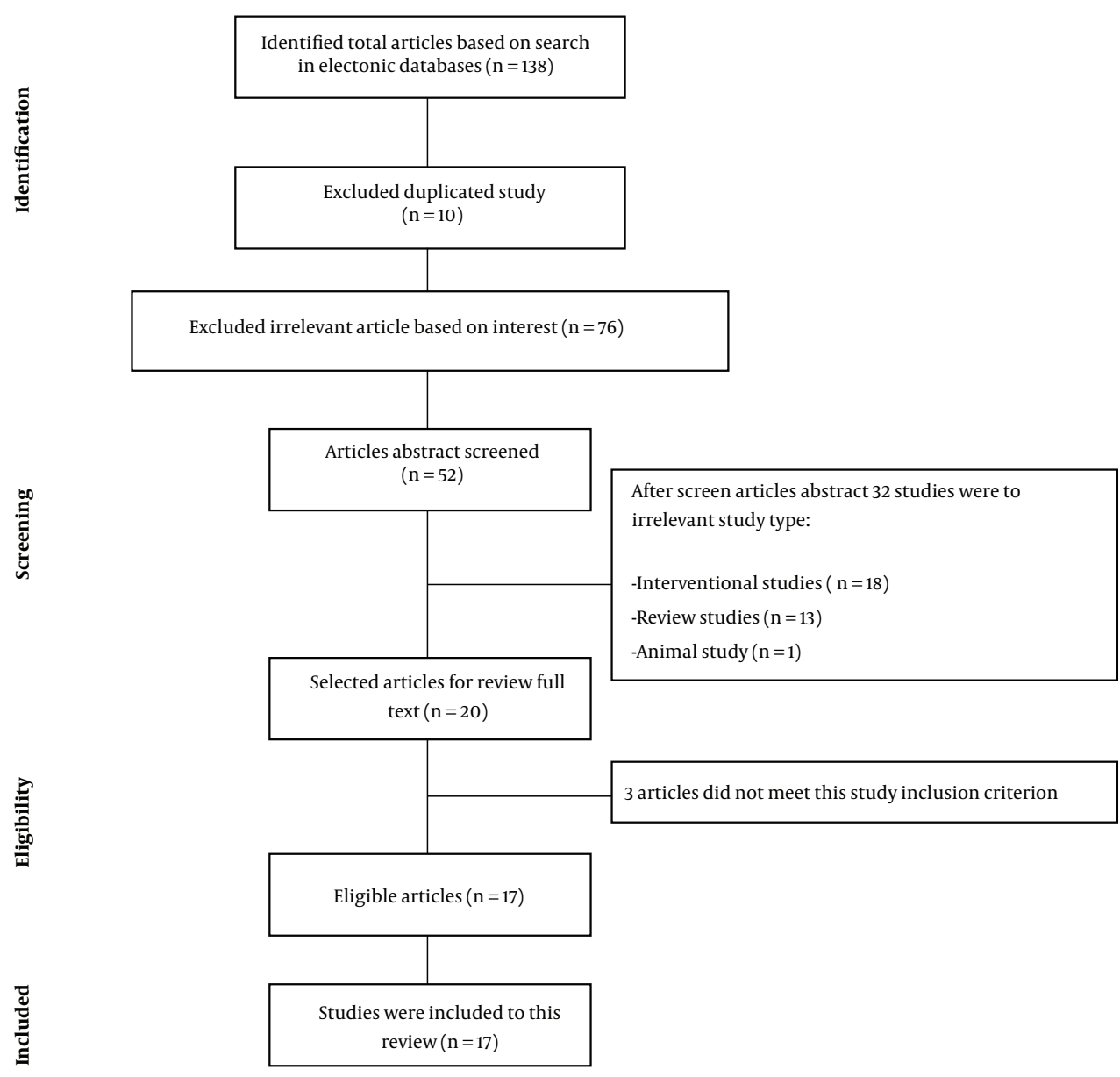

Figure 1. Flowchart of study selection

skipping meal, low calorie diet, low fat diet and low carbohydrates diet) $(3,8,14,19,24,29-31,36)$, exercise $(3,19,27$, 29-32), sauna, hot bath and room $(3,19,24,26,27,29,31,32)$, warm and plastic suits $(19,24,27,29,31,32)$, diet pills and drug (for example fat burner supplements, diuretics, laxatives and vomiting $(3,8,19,24,29,31,32,36)$, fluid restriction (19, 24, 29, 31, 36), spitting (3, 8, 24, 29, 31), and water loading (29). Six studies did not mention the used methods for RWL (9, 26, 28, 33-35). (Table 1) The weight loss duration was mentioned between 5 day and one week before competition in some reviewed studies $(3,9,14,28,29,35)$.

4.3. Effects of RWL on Physiological Status, Health-Related Parameters, Anthropometric Status, and Athletic Performance

\subsubsection{Physiological Status and Health-Related Parameters}

Among the reviewed studies, we found that the food restrictions could have adverse effects on physiological status, including dizziness, tension, anger, anger, confusion, anxiety, and fatigue (Table 2) $(14,15,32,36)$.

\subsubsection{Anthropometric Status}

Among anthropometric indices, weight was examined in the all reviewed studies except studies by Martinsen et al. (8) and Pettersson et al. (27). These studies reported weight loss before the competition among athletes. The other anthropometric index was body mass index (BMI), which was measured in studies by Filaire et al. (14), Brito et al. (19) and Berkovich et al. (24). In addition to anthropometric indices, the body composition was evaluated in seven studies $(9,14,19,28,33,35,36)$ in which reduction was observed in body fat (BF), fat free mass (FFM), and total body water (TBW) (Table 2 ).

\subsubsection{Athletic Performance}

In this literature review, Filaire et al. (14) and Hall et al. (15) observed that vigor was decreased after weight loss. Kordi et al. (36) reported that weight loss before competitions 


\begin{tabular}{|c|c|c|c|c|c|}
\hline Authors' Name & Country & Age, $y$ & Sample Size, $N$ & Kind of Sport & Common Methods Used RWL \\
\hline Filaire et al. (14) & France & $10 \pm 3.2$ & 11 & Judo & Dietary restriction \\
\hline Hall and Lane (15) & United Kingdom & $23.5 \pm 4.8$ & 16 & Box & - \\
\hline Alderman et al. (32) & Arizona & $15-18$ & 45 & Wrestle & $\begin{array}{l}\text { Exercise, sauna, hot bath and } \\
\text { room, warm and plastic suits, } \\
\text { diet pills and drug }\end{array}$ \\
\hline Ransone and Hughes (33) & United Status & 21.3 & 78 & Wrestle & - \\
\hline Artioli et al. (3) & Brazil & $19.3 \pm 5.3$ & 607 male and 215 female & Judo & $\begin{array}{l}\text { Dietary restriction, exercise, } \\
\text { sauna, hot bath and room, diet } \\
\text { pills and drug, spitting }\end{array}$ \\
\hline Martinsen et al. (8) & Norway & $15-16$ & 586 male and 375 female & Any type of elite sport & $\begin{array}{c}\text { Dietary restriction, diet pills and } \\
\text { drug, spitting }\end{array}$ \\
\hline Kazemi et al. (34) & Iran & $11-42$ & 72 male and 36 female & Taekwondo & - \\
\hline Kordi et al. (36) & Canada & $14-17$ & 436 male & Wrestle & $\begin{array}{l}\text { Dietary restriction, diet pills and } \\
\text { drug, fluid restriction }\end{array}$ \\
\hline Brito et al., 2012 (19) & Brazil & $25-74$ & 580 & $\begin{array}{l}\text { Judo, taekwondo, jujitsu, and } \\
\text { karate }\end{array}$ & $\begin{array}{l}\text { Dietary restriction, sauna, hot } \\
\text { bath and room, warm and } \\
\text { plastic suits, diet pills and drug, } \\
\text { fluid restriction }\end{array}$ \\
\hline Reljic et al. 2013 (9) & German & $19.2 \pm 9.2$ & 17 male & Box & - \\
\hline Pettersson et al. (27) & Sweden & $18-36$ & 9 male and 5 female & Judo, taekwondo, and wrestle & $\begin{array}{l}\text { Exercise, sauna, hot bath and } \\
\text { room, warm and plastic suits }\end{array}$ \\
\hline Mendes et al. (35) & Brazil & $19-25$ & 18 male & $\begin{array}{l}\text { Judo, wrestle, jujitsu, and mixed } \\
\text { marital arts }\end{array}$ & - \\
\hline Reljic et al. (28) & German & $19.2 \pm 9.2$ & 17 male & Box & - \\
\hline Berkovich et al. (24) & Israel & $12-17$ & 108 & Judo and box & $\begin{array}{l}\text { Dietary restriction, sauna, hot } \\
\text { bath and room, warm and } \\
\text { plastic suits, diet pills and drug, } \\
\text { fluid restriction, spitting }\end{array}$ \\
\hline da Silva Santos et al. (31) & Brazil & $15-30$ & 72 male and 44 female & Taekwondo & $\begin{array}{c}\text { Dietary restriction, exercise, } \\
\text { sauna, hot bath and room, } \\
\text { warm and plastic suits, diet pills } \\
\text { and drug, fluid restriction, } \\
\text { spitting }\end{array}$ \\
\hline Matthews and Nicholas (29) & United kingdom & $24.6 \pm 3.5$ & 7 & Mixed marital arts & $\begin{array}{l}\text { Dietary restriction, exercise, } \\
\text { sauna, hot bath and room, } \\
\text { warm and plastic suits, diet pills } \\
\text { and drug, fluid restriction, } \\
\text { spitting, water loading }\end{array}$ \\
\hline Dubnov-Raz et al. (30) & Israel & $12-21$ & 112 & Taekwondo & Dietary restriction, exercise \\
\hline
\end{tabular}

could cause weakness, muscle crumps, and myalgia. On the contrary, Mendes et al. (35) did not observe any change in the performance after weight loss (Table 2).

\subsection{Assessment of Dietary Intake in RWL Periods}

In the current study, four studies investigated dietary intake during weight loss $(14,28,29,35)$. Filaire et al. (14), Reljic et al. (28) and Mendes et al. (35) observed reduction in energy, carbohydrates, protein, fat, water, vitamins and minerals intake before competition. Matthews et al. (29) indicated increase of energy, carbohydrates, water and sodium after competition compared to the RWL period.

\section{Discussion}

As observed, the results of these studies indicate a high prevalence of RWL among athletes, especially one week before the start of competition. Athletes lose this weight to compete in a lower weight level than their usual weight, to face smaller and weaker athletes (3-6). Some studies have observed a direct relationship between weight loss and success of athletes in many sports around the world $(8,37)$. The results of studies often indicate the use of restrictions on the intake of liquids and foods for RWL within the days before the start of a competition $(32,38)$. At the same time, athletes at lower levels often use more dangerous methods 
Samadi M et al.

\begin{tabular}{|c|c|c|}
\hline Effects of RWL & Authors' Name & Outcome \\
\hline \multirow{3}{*}{$\begin{array}{l}\text { Physiological status and health-related } \\
\text { parameters }\end{array}$} & Filaire et al. (14) & \multirow{3}{*}{$\begin{array}{c}\text { Dietary restrictions can adverse effects on } \\
\text { physiological status including dizziness, } \\
\text { tension, anger, anger, confusion, anxiety, and } \\
\text { fatigue. }\end{array}$} \\
\hline & Hall et al. (15) & \\
\hline & Alderman et al.(32) & \\
\hline \multirow{10}{*}{ Anthropometric status } & Martinsen et al. (8) & \multirow{10}{*}{$\begin{array}{l}\text { Weight loss was showed before the competition } \\
\text { among of athletic as well as reduction of body } \\
\text { fat, fat free mass and total body water were } \\
\text { reported }(9,14,19,28,33,35,36) \text {. }\end{array}$} \\
\hline & Reljic et al. (9) & \\
\hline & Filaire et al. (14) & \\
\hline & Brito et al. (19) & \\
\hline & Berkovich et al. (24) & \\
\hline & Pettersson et al. (27) & \\
\hline & Reljic et al. (28) & \\
\hline & Ransone and Hughes (33) & \\
\hline & Mendes et al. (35) & \\
\hline & Kordi et al. (36) & \\
\hline \multirow{4}{*}{ Athletic performance } & Filaire et al. (14) & \multirow{4}{*}{$\begin{array}{l}\text { After weight loss, vigor was decreased while in } \\
\text { study by Mendes et al. ( } 35 \text { ), was not show any } \\
\text { effects on the performance after weight loss. }\end{array}$} \\
\hline & Hall et al. (15) & \\
\hline & Mendes et al. (35) & \\
\hline & Kordi et al. (36) & \\
\hline
\end{tabular}

to perform RWL, such as fasting and skipping meal (39). RWL often affects the amount of TBW (9). Short-term adjustment of body weight leads to a decrease in body water, electrolytes, glycogen and body tissue, which itself affects physiological functions, such as body temperature regulation $(10,11)$, cardiovascular function, and metabolic rate, which are highly important for exercise performance (12, 13).

Regarding the results, most athletes follow a lowcarbohydrate diet to carry out RWL. Considering that the supply of energy and body fluids to provide the fuel required during competition is important, following a lowcarbohydrate diet and the use of RWL can have negative effects on athletic performance (40). Sports drinks and carbohydrate supplements are items having benefits for their particular use, and have positive effects on athletic performance (41). If athletes consume adequate energy and body fluids, they will achieve the best results from every training session, and it is better to focus all dietary plans on carbohydrate-rich foods to provide the adequate amount of fuel for muscles (41). Furthermore, moderate amounts of protein and low-fat food sources are required to balance the diet, as well as some fruits and vegetables to provide vitamins and minerals (37). In addition, the deprivation of food and fluids during weight loss can negatively affect the athletes' mental status and increase tension, anger, fa- tigue, confusion and reduce their power. Restrictions on energy intake may result in changes in the mood of the individual and lead to an increased risk of developing eating disorders. Adherence to a weight loss regime is considered a trigger for the development and progression of eating disorders. These disorders can exacerbate symptoms, along with other factors such as exercise stress and personal mental impairment of fitness. Moreover, people who are on weight loss diets, do not always feel fully mentally prepared, and do not feel themselves to be in an ideal condition. Even dieting for short periods negatively affects individuals' mental abilities and $\operatorname{mood}(14,15)$. In addition, some studies indicate that RWL can induce a sense of being a champion in athletes. Psychological aspects of weight regulation that increases concentration, attitude of athletes' commitment before the tournament, and creation of a psychological advantage over rivals contribute to the success of athletes as much as physical aspects (38). Considering that athletes are more exposed to oxidative damage, it is reported that RWL can have detrimental effects on antioxidant status. This is probably because RWL diets often contain a high proportion of PUFA and fewer carbohydrates. High levels of PUFA, through lipid oxidation and by forming lipid peroxide, cause cell wall destruction and oxidative damage (42). Additionally, some studies have demonstrated the effects of RWL on growth hormone 
secretion in adolescents, and its negative impacts on puberty, causing a significant reduction in growth hormone during weight loss period in adolescents $(43,44)$. Overall, reduced energy and micronutrient intakes, inducing a RWL, could be a limiting factor to training adaptations and a threat to athletes' health if frequently used (45).

Our study had some limitations, so that the results of the study were not expressed in terms of a systematic review and meta-analysis. Furthermore, risk of bias in this study was not assessed.

\subsection{Conclusions}

Regarding the negative effects of short-term weight adjustment on physiological functions, including as athletes' body temperature regulation, cardiovascular function, metabolism, and mental status (such as increased tension and fatigue), and since it has been observed that providing adequate energy and body fluids help athletes to achieve the best training results, studies have recommended concentrating all dietary plans on carbohydraterich diets. These provide adequate energy while receiving moderate amounts of protein and low-fat food to reach a balanced diet, as well as providing fruits and vegetables to supply vitamins and minerals in athletes. Further studies are necessary to obtain a better understanding of the connection between RWL and performance of athletes. Future studies should consider these issues separately for different types of sports as well as at different ages from adolescence to adulthood.

\section{Acknowledgments}

The authors would like to thank Kermanshah University of Medical Sciences for its cooperation in all stages of this study.

\section{Footnotes}

Authors' Contribution: Study concept and design: Mehnoosh Samadi, Miaad Chaghazardi, and Shima Moradi. Analysis and interpretation of data: Shima Moradi, Sheno Karimi, and Mohammad Hozoori. Drafting of the manuscript: Shima Moradi, Amir Bagheri, and Karimi. Critical revision of the manuscript for important intellectual content: Shima Moradi, Mehnoosh Samadi, and Yahya Pasdar.

Conflict of Interests: Authors mention that there is no conflict of interest in this study.

Ethical Approval: The present study was approved by Research Council of Kermanshah University of Medical Sciences (code: KUMS.REC.1396.452).
Funding/Support: Research has been supported by Research Council of Kermanshah University of Medical Sciences (code: 96452).

\section{References}

1. Kordi R, Maffuli N, Wroble R, Wallace W. Nutrition in combat sports. London: Springer-Verlag; 2009.

2. Langan-Evans C, Close GL, Morton JP. Making weight in combat sports. Strength Cond J. 2011;33(6):25-39. doi: 10.1519/SSC.0b013e318231bb64.

3. Artioli GG, Gualano B, Franchini E, Scagliusi FB, Takesian M, Fuchs $\mathrm{M}$, et al. Prevalence, magnitude, and methods of rapid weight loss among judo competitors. Med Sci Sports Exerc. 2010;42(3):436-42. doi: 10.1249/MSS.ob013e3181ba8055. [PubMed:19952804].

4. Kiningham RB, Gorenflo DW. Weight loss methods of high school wrestlers. Med Sci Sports Exerc. 2001;33(5):810-3. doi: 10.1097/00005768-200105000-00021. [PubMed: 11323553].

5. Oppliger RA, Case HS, Horswill CA, Landry GL, Shelter AC. American College of Sports Medicine position stand. Weight loss in wrestlers. Med Sci Sports Exerc. 1996;28(6):ix-xii. [PubMed: 8926865].

6. Steen SN, Brownell KD. Patterns of weight loss and regain in wrestlers: has the tradition changed? Med Sci Sports Exerc. 1990;22(6):762-8. doi: 10.1249/00005768-199012000-00005. [PubMed: 2287253].

7. Von Duvillard SP, Braun WA, Markofski M, Beneke R, Leithauser R. Fluids and hydration in prolonged endurance performance. Nutrition. 2004;20(7-8):651-6. doi: 10.1016/j.nut.2004.04.011. [PubMed:15212747].

8. Martinsen M, Bratland-Sanda S, Eriksson AK, Sundgot-Borgen J. Dieting to win or to be thin? A study of dieting and disordered eating among adolescent elite athletes and non-athlete controls. $\mathrm{Br} J$ Sports Med. 2010;44(1):70-6. doi:10.1136/bjsm.2009.068668. [PubMed: 20026698]

9. Reljic D, Hassler E, Jost J, Friedmann-Bette B. Rapid weight loss and the body fluid balance and hemoglobin mass of elite amateur boxers. $J$ Athl Train. 2013;48(1):109-17. doi: 10.4085/1062-6050-48.1.05. [PubMed: 23672332]. [PubMed Central: PMC3554025].

10. Casa DJ, Armstrong LE, Hillman SK, Montain SJ, Reiff RV, Rich BS, et al. National athletic trainers' association position statement: Fluid replacement for athletes. J Athl Train. 2000;35(2):212-24. [PubMed: 16558633]. [PubMed Central: PMC1323420].

11. Sawka MN, Latzka WA, Matott RP, Montain SJ. Hydration effects on temperature regulation. Int J Sports Med.1998;19 Suppl 2:S108-10. doi 10.1055/s-2007-971971. [PubMed: 9694412].

12. Allen TE, Smith DP, Miller DK. Hemodynamic response to submaximal exercise after dehydration and rehydration in high school wrestlers. Med Sci Sports. 1977;9(3):159-63. [PubMed: 593078].

13. Fogelholm M. Effects of bodyweight reduction on sports performance. Sports Med. 1994;18(4):249-67. doi: 10.2165/00007256199418040-00004. [PubMed: 7817064].

14. Filaire E, Maso F, Degoutte F, Jouanel P, Lac G. Food restriction, performance, psychological state and lipid values in judo athletes. Int J Sports Med. 2001;22(6):454-9. doi: 10.1055/s-2001-16244. [PubMed: 11531040].

15. Hall CJ, Lane AM. Effects of rapid weight loss on mood and performance among amateur boxers. Br J Sports Med. 2001;35(6):3905. doi: 10.1136/bjsm.35.6.390. [PubMed: 11726472]. [PubMed Central: PMC1724425].

16. Degoutte F, Jouanel P, Begue RJ, Colombier M, Lac G, Pequignot JM, et al. Food restriction, performance, biochemical, psychological, and endocrine changes in judo athletes. Int J Sports Med. 2006;27(1):9-18. doi: 10.1055/s-2005-837505. [PubMed: 16388436].

17. Horswill CA, Park SH, Roemmich JN. Changes in the protein nutritional status of adolescent wrestlers. Med Sci Sports Exerc. 1990;22(5):599-604. doi: 10.1249/00005768-199010000-00010. [PubMed: 2233198]. 
18. Artioli GG, Scagliusi F, Kashiwagura D, Franchini E, Gualano B, Junior AL. Development, validity and reliability of a questionnaire designed to evaluate rapid weight loss patterns in judo players. Scand J Med Sci Sports. 2010;20(1):e177-87. doi: 10.1111/j.1600-0838.2009.00940.x. [PubMed: 19793217].

19. Brito CJ, Roas A, Brito I, Marins J, Cordova C, Franchini E. Methods of body mass reduction by combat sport athletes. Int J Sport Nutr Exerc Metab. 2012;22(2):89-97. doi: 10.1123/ijsnem.22.2.89. [PubMed: 22349031].

20. Kazemi M, Shearer H, Choung YS. Pre-competition habits and in juries in taekwondo athletes. BMC Musculoskelet Disord. 2005;6:26. doi: 10.1186/1471-2474-6-26. [PubMed: 15921510]. [PubMed Central: PMC1168901].

21. Tsai ML, Chou KM, Chang CK, Fang SH. Changes of mucosal immunity and antioxidation activity in elite male Taiwanese taekwondo athletes associated with intensive training and rapid weight loss. Br J Sports Med. 2011;45(9):729-34. doi: 10.1136/bjsm.2009.062497. [PubMed: 19846424].

22. Peron A, Zampronha Filho W, da Silva Garcia L, da Silva AW, Alvarez JFG. Perfil nutricional de boxeadores olimpicos e avaliacao do impacto da intervencao nutricional no ajuste de peso para as categorias de lutas. Mundo saude. 2009;33(3):352-7.

23. Joy JM, Lowery RP, Wilson JM, Purpura M, De Souza EO, Wilson SM, et al. The effects of 8 weeks of whey or rice protein supplementation on body composition and exercise performance. Nutr J. 2013;12:86. doi: 10.1186/1475-2891-12-86. [PubMed: 23782948]. [PubMed Central: PMC3698202].

24. Berkovich BE, Eliakim A, Nemet D, Stark AH, Sinai T. Rapid weight loss among adolescents participating in competitive judo. Int J Sport Nutr Exerc Metab. 2016;26(3):276-84. doi: 10.1123/ijsnem.2015-0196. [PubMed: 26479490].

25. Moher D, Shamseer L, Clarke M, Ghersi D, Liberati A, Petticrew M et al. Preferred reporting items for systematic review and metaanalysis protocols (PRISMA-P) 2015 statement. Syst Rev. 2015;4:1 doi: 10.1186/2046-4053-4-1. [PubMed: 25554246]. [PubMed Central: PMC4320440]

26. [No authors listed]. Information on the STROBE Initiative. 2017. Available from: https://www.strobe-statement.org/index.php?id=strobehome.

27. Pettersson S, Ekstrom MP, Berg CM. Practices of weight regulation among elite athletes in combat sports: a matter of mental advantage? J Athl Train. 2013;48(1):99-108. doi: 10.4085/1062-6050-48.1.04. [PubMed: 23672331]. [PubMed Central: PMC3554040].

28. Reljic D, Jost J, Dickau K, Kinscherf R, Bonaterra G, Friedmann-Bette B. Effects of pre-competitional rapid weight loss on nutrition, vitamin status and oxidative stress in elite boxers. J Sports Sci. 2015;33(5):43748. doi: 10.1080/02640414.2014.949825. [PubMed: 25259507].

29. Matthews JJ, Nicholas C. Extreme Rapid Weight Loss and Rapid Weight Gain Observed in UK Mixed Martial Arts Athletes Preparing for Competition. Int J Sport Nutr Exerc Metab. 2017;27(2):122-9. doi: 10.1123/ijsnem.2016-0174. [PubMed: 27710145].

30. Dubnov-Raz G, Mashiach-Arazi Y, Arieli R, Raz R, Constantini NW. [Eating attitudes and pre-competition rapid weight loss in young taekwondo fighters]. Harefuah. 2016;155(6):343-7. 387. Hebrew. [PubMed: 27544985].

31. da Silva Santos JF, Takito MY, Artioli GG, Franchini E. Weight loss practices in Taekwondo athletes of different competitive levels. $J E x$ erc Rehabil. 2016;12(3):202-8. doi: 10.12965/jer.1632610.305. [PubMed: 27419116]. [PubMed Central: PMC4934965].
32. Alderman B, Landers DM, Carlson J, Scott JR. Factors related to rapid weight loss practices among internationalstyle wrestlers. Med Sci Sports Exerc. 2004;36(2):249-52. doi: 10.1249/01.MSS.0000113668.03443.66. [PubMed: 14767247].

33. Ransone J, Hughes B. Body-Weight Fluctuation in Collegiate Wrestlers: Implications of the National Collegiate Athletic Association Weight-Certification Program. J Athl Train. 2004;39(2):162-5. [PubMed: 15173868]. [PubMed Central: PMC419511].

34. Kazemi M, Rahman A, De Ciantis M. Weight cycling in adolescent Taekwondo athletes. J Can Chiropr Assoc. 2011;55(4):318-24. [PubMed: 22131569]. [PubMed Central: PMC3222708].

35. Mendes SH, Tritto AC, Guilherme JP, Solis MY, Vieira DE, Franchini $\mathrm{E}$, et al. Effect of rapid weight loss on performance in combat sport male athletes: does adaptation to chronic weight cycling play a role? Br J Sports Med. 2013;47(18):1155-60. doi: 10.1136/bjsports-2013-092689. [PubMed: 24047570].

36. Kordi R, Ziaee V, Rostami M, Wallace WA. Patterns of weight loss and supplement consumption of male wrestlers in Tehran. Sports Med Arthrosc Rehabil Ther Technol. 2011;3(1):4. doi: 10.1186/1758-2555-3-4. [PubMed: 21314982]. [PubMed Central: PMC3055235].

37. Houston ME, Marrin DA, Green HJ, Thomson JA. The Effect of Rapid Weight Loss on Physiological Functions in Wrestlers. Phys Sportsmed. 1981;9(11):73-8. doi: 10.1080/00913847.1981.11711208. [PubMed: 27410981].

38. Choma CW, Sforzo GA, Keller BA. Impact of rapid weight loss on cognitive function in collegiate wrestlers. Med Sci Sports Exerc. 1998;30(5):746-9. doi: 10.1097/00005768-199805000-00016. [PubMed: 9588618].

39. Koral J, Dosseville F. Combination of gradual and rapid weight loss: Effects on physical performance and psychological state of elite judo athletes. J Sports Sci. 2009;27(2):115-20. doi: 10.1080/02640410802413214. [PubMed: 19058087]

40. Garthe I, Raastad T, Refsnes PE, Koivisto A, Sundgot-Borgen J. Effect of two different weight-loss rates on body composition and strength and power-related performance in elite athletes. Int J Sport Nutr Exerc Metab. 2011;21(2):97-104. doi: 10.1123/ijsnem.21.2.97. [PubMed: 21558571].

41. Hozoori M, Safaei-Motlagh A, Marzban A. The epidemiology of dietary supplements consumption in the athletes of Karaj Iran. Int J Epidemiol Res. 2016;3(3):222-31. doi: 10.1080/02640414.2011.565783. [PubMed: 21500080].

42. Sundgot-Borgen J, Garthe I. Elite athletes in aesthetic and Olympic weight-class sports and the challenge of body weight and body compositions. J Sports Sci. 2011;29 Suppl 1:S101-14. doi: 10.1080/02640414.2011.565783. [PubMed: 21500080].

43. Abedelmalek S, Chtourou $\mathrm{H}$, Souissi N, Tabka Z. Caloric restriction effect on proinflammatory cytokines, growth hormone, and steroid hormone concentrations during exercise in judokas. Oxid Med Cell Longev. 2015;2015:809492. doi: 10.1155/2015/809492. [PubMed: 26075039]. [PubMed Central: PMC4446567].

44. Shekelle PG, Hardy ML, Morton SC, Maglione M, Mojica WA, Suttorp MJ, et al. Efficacy and safety of ephedra and ephedrine for weight loss and athletic performance: A meta-analysis. JAMA. 2003;289(12):153745. doi: 10.1001/jama.289.12.1537. [PubMed: 12672771].

45. Durguerian A, Bougard C, Drogou C, Sauvet F, Chennaoui M, Filaire E. Weight loss, performance and psychological related states in highlevel weightlifters. Int J Sports Med. 2016;37(3):230-8. doi: 10.1055/s0035-1555852. [PubMed: 26701827]. 